\title{
The assessment of esophageal pressure using different devices: a validation study
}

\begin{abstract}
avide CHIUMELLO 1,2,3*, Alessio CACCIOPPOLA 1, Tommaso POZZI 1, Andrea C. LUSARDI 1, Valentina DE GIORGIS 1, Valentina GALANTI 1, Erica FERRARI 1, Silvia COPPOLA 1

Department of Anesthesia and Intensive Care, ASST Santi Paolo e Carlo, San Paolo University Hospital, Milan, aly; ${ }^{2}$ Department of Health Sciences, University of Milan, Milan, Italy; ${ }^{3}$ Coordinated Research Center on Resiratory Failure, University of Milan, Milan, Italy

Corresponding author: Davide Chiumello, Department of Anesthesia and Intensive Care, ASST Santi Paolo e Carlo Via Di Rudinì, ilan, Italy. E-mail: davide.chiumello@unimi.it
\end{abstract}

BACKGROUND: Although esophageal pressure measurement could help clinicians to improve the ventilatory management of acute respiratory distress syndrome (ARDS) patients, it has been mainly used in clinical research. Aim of this study was to compare the measurements of end-expiratory esophageal pressure, end-expiratory transpulmonary pressure and lung stress by three systems: a dedicated manual device, taken as gold standard, a new automatic system (Optivent) nd a bedside equipment, consisting of a mechanical ventilator and a hemodynamic monitor.

METHODS: In sedated and paralyzed mechanically ventilated ARDS patients the esophageal pressure was measured at hree PEEP levels in random fashion (baseline level, 50\% higher and 50\% lower).

RESULTS: Forty patients were enrolled (BMI 25 [23-28] kg/m², $\mathrm{PaO}_{2} / \mathrm{FiO}_{2} 187$ [137-223] and PEEP 9 $\pm 3 \mathrm{cmH} \mathrm{H}_{2} \mathrm{O}$ ). The mean esophageal pressure measured during an expiratory pause by the dedicated system, the bedside system and Optivent were $10.0 \pm 4.2,10 \pm 4$ and $9.9 \pm 4.0 \mathrm{cmH}_{2} \mathrm{O}$, respectively. The respective bias and limits of agreement between the edicated system and Optivent and between the dedicated system and the bedside system were as follows: end-expiratory sophageal pressure, $0.2 \mathrm{cmH}_{2} \mathrm{O},(-0.4$ to 0.9$)$ and $-0.1 \mathrm{cmH}_{2} \mathrm{O}(-1.9$ to 1.7$)$; end-expiratory transpulmonary pressure, -0.6 $\mathrm{cmH}_{2} \mathrm{O}(-1.7$ to 0.4$)$ and $-0.4 \mathrm{cmH}_{2} \mathrm{O},(-2.2$ to 1.5$)$; lung stress $-0.9 \mathrm{cmH}_{2} \mathrm{O}(-3.0$ to 1.1$)$ and $-1.5 \mathrm{cmH}_{2} \mathrm{O}(-4.4$ to 1.4$)$. CONCLUSIONS: Both Optivent and the bedside system showed clinically acceptability if compared to the gold standard device. The possibility to apply one of these systems could allow a wider use of esophageal pressure in clinical practice.

Cite this article as: Chiumello D, Caccioppola A, Pozzi T, Lusardi AC, De Giorgis V, Galanti V, et al. The assessment of esophageal pressure using different devices: a validation study. Minerva Anestesiol 2020;86:1047-56. DOI: 10.23736/S03759393.20.14458-4)

KEY WORDS: Respiratory mechanics; Respiratory distress syndrome, adult; Monitoring, physiologic. tients with acute respiratory distress syndrome (ARDS), it is used not only to improve gas exchange, but also to reduce the work of breathing. ${ }^{1,2}$ However, ARDS still presents a high mortality rate, that could be partially due to the mechanical ventilation per se, as it could promote several types of injures, which are collectively named as ventilator induced lung injury (VILI). ${ }^{3}$ A possible way to decrease VILI is to avoid or re- duce an excessive lung expansion during the inflation (lung stress/strain) and alveolar collapse at the end of expiration by using an adequate PEEP level. ${ }^{1,2}$ The respiratory system is constituted by the lung and the chest wall, thus a similar airway pressure applied by the mechanical ventilator, could have different effects on lung and chest wall expansion according to their mechanical characteristics. ${ }^{4,} 5$ It has been reported that abnormalities in the respiratory mechanics were mainly due to alterations in the lungs rather than in the chest 


\section{COPYRIGHT $^{\circledR} 2020$ EDIZIONI MINERVA MEDICA}

wall.6, 7 ARDS patients can present significant alterations in the chest wall mechanical properties, due to the presence of intra-abdominal hypertension or pleural effusion..$^{8-10}$ Consequently, airway pressure, commonly considered as a surrogate of the lung distension, cannot accurately reflect it, because the lung expanding pressure is due to the difference between the airway and the pleural pressure, that is the pressure outside the lung. ${ }^{11,12}$ Several previous studies reported that changes in pleural pressure could be assessed by changes in esophageal pressure. ${ }^{13}, 14$ Since then, recent data showed the usefulness of esophageal pressure measurements in passive mechanically ventilated patients in titrating the PEEP according to the end-expiratory transpulmonary pressure, in computing lung stress at end-inspiration and in measuring chest wall and lung elastances. In addition, esophageal pressure can be assessed in active patients to detect patient's asynchronies and to measure the work of breathing. 11, 12

Although esophageal pressure measurements could improve the ventilatory management of ARDS patients, it has been mainly used in clinical research and not in daily clinical practice. The most reported reasons for that are the technical difficulties and the inability to obtain easy and accurate measurements. ${ }^{11,12}$ Recently, a new automatic monitoring system (Optivent, Sidam Srl, Modena, Italy), which is able to directly measure both airway pressure and esophageal pressure has been released.

The aim of this study was to compare the measurements of respiratory mechanics in ARDS patients by using a dedicated manual device (constituted by a pressure transducer with a software recording system), taken as gold standard, with those obtained by two other systems: Optivent and a bedside equipment, consisting of a mechanical ventilator and a hemodynamic monitor. In particular, we focused on three variables: endexpiratory esophageal pressure, end-expiratory transpulmonary pressure and lung stress.

\section{Materials and methods}

\section{Study population}

All consecutive mechanically ventilated patients admitted in the intensive care unit (ICU) from
February 2019 to September 2019, affected with ARDS according to the Berlin definition, ${ }^{15}$ requiring an esophageal catheter for clinical reasons to assess the respiratory mechanics were considered eligible for the study. The study was approved by the Institutional Review board of our hospital (Comitato Etico Interaziendale Milano Area A, n. 7154/2019, approved 18.02.2019) and informed consent was obtained according to the Italian regulations. Exclusion criteria were the presence of hemodynamic instability, barotrauma, esophageal diseases and severe coagulopathy.

\section{Study design}

Patients in supine position, sedated and paralyzed, were ventilated in volume-controlled, with a tidal volume between $6-8 \mathrm{~mL} / \mathrm{kg}$ of predicted body weight and using a square wave inspiratory flow. For each patient the measurements were performed by three different methods (described below) at three consecutive levels of PEEP, randomly applied: baseline level, 50\% higher and $50 \%$ lower. Respiratory rate was selected to maintain an arterial pH between 7.30 and 7.45. An end-inspiratory and an end-expiratory pause have been performed at each PEEP level.

\section{Esophageal catheter}

Esophageal pressure was measured by using a radiopaque catheter equipped with a balloon in the lower part (Nutrivent, Sidam Srl., Modena, Italy). Before the insertion the esophageal catheter was emptied of air and closed with a threeway stopcock. Then, it was introduced transorally and advanced to reach the stomach (generally at a least depth of $55 \mathrm{~cm}$ from the mouth). The balloon was inflated with an air volume of 4 $\mathrm{mL}$. The intragastric position of the catheter was confirmed by a rise in intra-abdominal pressure following external manual epigastric compression. Finally, it was retracted into the esophagus (i.e. confirmed by the presence of cardiac artifacts in the pressure tracing and by the difference in the absolute pressure), at a distance between 40-45 cm from the mouth. An occlusion test, consisting in the application of four manual thoracic compression during an end-expiratory hold while simultaneously recording the esophageal 


\section{COPYRIGHT $^{\circledR} 2020$ EDIZIONI MINERVA MEDICA}

and airway pressure was performed. The optimal position of the esophageal catheter was found according to the highest ratio between the esophageal and the airway pressure. ${ }^{16}$

\section{Measurements acquisition}

The measurement setting is shown in Supplementary Digital Material 1 (Supplementary Figure 1).

\section{Optivent system}

Optivent (SIDAM Srl, Modena, Italy) is an automatic system composed by a touchscreen monitor that is directly connected to the patient. Real time airway pressure and esophageal pressure are displayed on the screen. Airway pressure was measured using a disposable transducer (Hamilton Medical ventilators, Hamilton Medical AG, Bonaduz, Switzerland) inserted between the endotracheal tube and the ventilator circuit. Calibration procedures are automatically performed by the device after the connection with the sensor, in fact it is a self-calibrating system. Sample rate of pressure transducer is ranged between 50$200 \mathrm{~Hz}$ with a filter of frequency of $2.5 \mathrm{~Hz}$.

\section{Bedside system}

This hybrid system is composed by the mechanical ventilator and the hemodynamic monitor. The airway pressure was directly measured and recorded by the ventilator; the esophageal pressure was measured by a pressure transducer, the same used to measure the arterial pressure but filled with a column of air, instead of $0.9 \%$ saline (TruWave/VAMP Plus, Edwards Lifesciences, Unterschleissheim) connected to the hemodynamic monitor (Philips INTELLIvue MX800; Koninklijke Philips N.V. Amsterdam, the Netherlands). Data of the airway pressure and esophageal pressure were acquired from the screen of the mechanical ventilator and hemodynamic monitor, respectively. The values of esophageal pressure are acquired in millimeters of mercury and consequently converted in centimeters of water (1 $\mathrm{mmHg}=1.36 \mathrm{cmH}_{2} \mathrm{O}$. Three types of mechanical ventilator (Draeger Evita XL, Draeger AG \& Co. KGaA, Lubecca, Germany; Mindray SV800, Shenzhen Mindray Bio-Medical Electronics Co.,
Shenzhen, China; and Hamilton S1, Hamilton Medical AG, Bonaduz, Switzerland) were used. The calibration of the pressure transducer consists in zeroing through two steps: first, the air interface is opened to atmospheric pressure, then the monitor's zeroing function key or button is pressed: zeroing electronically establishes for the monitor atmospheric pressure as the atmospheric zero reference point. Sample rate of pressure transducer is ranged between $40 \mathrm{~Hz}$ with a filter of frequency of $5 \mathrm{~Hz}$.

\section{Dedicated system}

The airway and esophageal pressure were measured by pressure transducers (MPX 2010 DP. Motorola, Solna, Sweden) and recorded on a personal computer using a specific software for subsequent analysis (Colligo, Elekton, Milan, Italy). Before each recording, zeroing is performed opening the pressure transducer to atmospheric pressure and setting the atmospheric pressure as zero reference point. We assumed the dedicated system as the gold standard method as it is an in vitro calibrated by a column of water and specifically built system, which provides the best technical characteristics for measuring these variables. Moreover, it is the device we have more experience because we performed most of our studies using this system. Sample rate of pressure transducer is ranged between $50-100 \mathrm{~Hz}$ with a filter of frequency of $5 \mathrm{~Hz}$.

The accuracy of the devices in measuring pressures is $4 \%$ of the measured value for the ventilator and hemodynamic monitor (as reported by the user's manuals), $\pm 0.5 \mathrm{cmH}_{2} \mathrm{O}$ for the Optivent system and $\pm 0.1 \mathrm{cmH}_{2} \mathrm{O}$ for the dedicated system (Personal communication from Sidam and Elekton).

\section{Measurements computation}

During end-inspiratory and end-expiratory pauses the following variables were measured: the absolute airway pressures and esophageal pressures. The end-expiratory transpulmonary pressure and lung stress were computed accordingly to previously published formula (Supplementary Digital Material 2: Supplementary Text File 1).4, 17, 18 The mean of 4 pauses was used. 


\section{COPYRIGHT $^{\circledR} 2020$ EDIZIONI MINERVA MEDICA}

\section{Statistical analysis}

Data are expressed as mean \pm standard deviation (D'Agostino-Pearson omnibus normality test), or median [interquartile range] as appropriate. A linear correlation was carried out between each system and correlation coefficients were calculated. The statistical analysis was performed using GraphPad PRISM 8.0 (GraphPad Software, San Diego, CA, USA). The degree of agreement between systems was determined using the Bland-Altman method (difference $v s$. average). ${ }^{19}$ The statistical significance cut off will be considered as a $P$ value $<0.05$.

We enrolled a number of patients to ensure the confidence intervals of the bias and of the limit of agreement for each device and each investigated variable were below the accuracy levels of each device.

\section{Results}

Forty ARDS patients were enrolled. The baseline clinical characteristics are shown in Table I. Three PEEP levels were evaluated: baseline PEEP $9 \pm 3 \mathrm{cmH}_{2} \mathrm{O}, 50 \%$ higher PEEP $12 \pm 3 \mathrm{~cm}$ -

\section{TABLE I.-Baseline characteristics of the study popula- tion.}

\begin{tabular}{lc}
\hline Number of patients (N.) & 40 \\
Age $(\mathrm{yr})$ & $71[56-79]$ \\
Female \% (N.) & $30(12)$ \\
$\mathrm{Height}(\mathrm{cm})$ & $170 \pm 9$ \\
$\mathrm{BMI}\left(\mathrm{kg} / \mathrm{m}^{2}\right)$ & $25[23-28]$ \\
$\mathrm{PaO}_{2} / \mathrm{FiO}_{2}$ & $187[137-223]$ \\
$\mathrm{PaCO}_{2}(\mathrm{mmHg})$ & $44.0 \pm 8.1$ \\
$\mathrm{ARDS}^{2}$ category \% (N.) & \\
Mild & $43(17)$ \\
Moderate & $50(20)$ \\
Severe & $7(3)$ \\
Cause of ARDS \% (N.) & \\
Pulmonary & $67(27)$ \\
Extrapulmonary & $33(13)$ \\
Time from admission to study (days) & $1[1-2]$ \\
Respiratory rate (breaths per minute) & $16 \pm 2$ \\
Tidal volume (mL) & $482 \pm 85$ \\
Tidal volume / predicted body weight $(\mathrm{mL} / \mathrm{kg})$ & $6.6 \pm 1.3$ \\
Clinical PEEP $\left(\mathrm{cmH} \mathrm{H}_{2} \mathrm{O}\right)$ & $9 \pm 3$ \\
Minute ventilation $(\mathrm{L} /$ minute) & $8.0 \pm 1.9$ \\
Driving pressure (cmH $\left.{ }_{2} \mathrm{O}\right)$ & $9[7-12]$ \\
\hline
\end{tabular}

Quantitative data are expressed as mean (standard deviation, SD) or median [interquartile range] as appropriate. Categorical data are presented as $\mathrm{N}$ (number of subjects) and percentages (\%).

BMI: Body Mass Index; ARDS: acute respiratory distress syndrome; PEEP: positive end-expiratory pressure.
$\mathrm{H}_{2} \mathrm{O}$ and $50 \%$ lower PEEP $5 \pm 2 \mathrm{cmH}_{2} \mathrm{O}$. Tidal volume remained constant at $482 \pm 85 \mathrm{~mL}$.

\section{End-expiratory esophageal pressure}

The mean end-expiratory esophageal pressures, respectively acquired by the dedicated system, the bedside system and by Optivent, were $10.0 \pm 4.2, \quad 10.0 \pm 4.0$ and $9.9 \pm 4.0 \mathrm{cmH}_{2} \mathrm{O}$. As shown in Figure 1, both Optivent and the bedside system exhibited a high level of correlation with the dedicated system $\left(\mathrm{r}^{2}=0.99, \mathrm{P}<0.0001\right.$ and $\mathrm{r}^{2}=0.95, \mathrm{P}<0.0001$, respectively). The BlandAltman plot showed a bias of $0.2 \mathrm{cmH}_{2} \mathrm{O}(95 \%$ CI: 0.2 to 0.3$)$, with limits of agreement $( \pm 1.96$ SD) from $-0.4 \mathrm{cmH}_{2} \mathrm{O}(95 \% \mathrm{CI}:-0.5$ to -0.3$)$ to $0.9 \mathrm{cmH}_{2} \mathrm{O}(95 \%$ CI: 0.8 to 1.0$)$ for the Optivent compared with the dedicated system, and a bias of $-0.1 \mathrm{cmH}_{2} \mathrm{O}(95 \% \mathrm{CI}:-0.3$ to 0.1$)$, with limits of agreement $( \pm 1.96 \mathrm{SD})$ from $-1.9 \mathrm{cmH}_{2} \mathrm{O}(95 \%$ CI: -2.2 to -1.6$)$ to $1.7 \mathrm{cmH}_{2} \mathrm{O}(95 \% \mathrm{CI}: 1.4$ to 2.0) for the bedside system compared with the dedicated system (Figure 1). Linear regression and Bland-Altman plots of Optivent compared to the bedside system are shown in Supplementary Digital Material 3 (Supplementary Figure 2).

\section{End-expiratory transpulmonary pressure}

The mean end-expiratory transpulmonary pressures, respectively computed with data acquired by the dedicated system, the bedside system and by Optivent, were $-1.6 \pm 4.6,-1.4 \pm 4.5$ and $-1.2 \pm 4.3 \mathrm{cmH}_{2} \mathrm{O}$. As shown in Figure 2, both Optivent and the bedside system exhibited a high level of correlation with the dedicated system $\left(\mathrm{r}^{2}=0.99, \mathrm{P}<0.0001\right.$ and $\mathrm{r}^{2}=0.96, \mathrm{P}<0.0001$, respectively). The Bland-Altman plot showed a bias of $-0.6 \mathrm{cmH}_{2} \mathrm{O}(95 \% \mathrm{CI}$ : -0.8 to -0.5$)$, with limits of agreement $( \pm 1.96 \mathrm{SD})$ from $-1.7 \mathrm{~cm}$ $\mathrm{H}_{2} \mathrm{O}(95 \% \mathrm{CI}:-1.9$ to -1.5$)$ to $0.4 \mathrm{cmH}_{2} \mathrm{O}(95 \%$ CI: 0.2 to 0.6$)$ for the Optivent compared with the dedicated system, and a bias of $-0.4 \mathrm{cmH}_{2} \mathrm{O}$ (95\% CI: -0.6 to -0.2 ), with limits of agreement $( \pm 1.96 \mathrm{SD})$ from $-2.2 \mathrm{cmH}_{2} \mathrm{O}(95 \% \mathrm{CI}:-2.5$ to $-1.9)$ to $1.5 \mathrm{cmH}_{2} \mathrm{O}(95 \% \mathrm{CI}$ : 1.2 to 1.8$)$ for the bedside system compared with the dedicated system (Figure 2). Linear regression and BlandAltman plots of Optivent compared to the bedside system are shown in Supplementary Digital Material 4 (Supplementary Figure 3). 


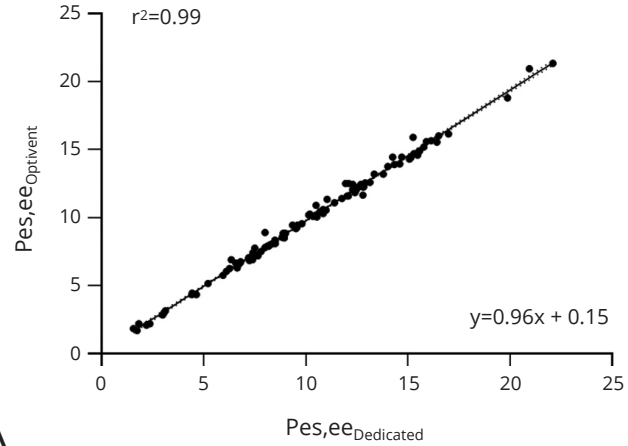

A

Pes,ee Dedicated $_{\text {}}$

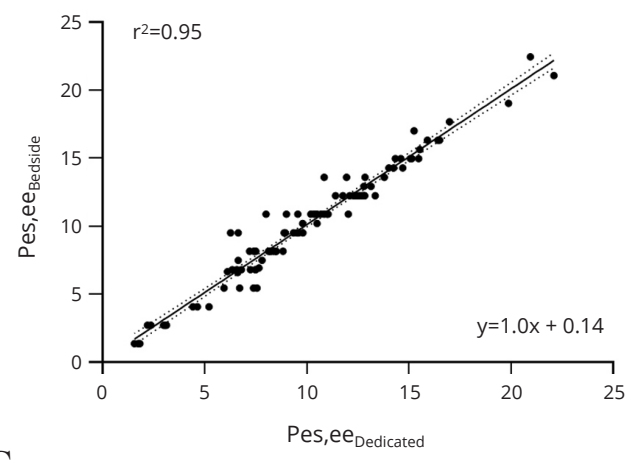

C

Figure 1.-Accuracy of Optivent and of the bedside system in measuring end-expiratory esophageal pressure compared to the dedicated system. A) Linear regression plot between Optivent and the dedicated system. The end-expiratory esophageal pressure obtained by Optivent $\left(\mathrm{Pes}, \mathrm{e}_{\text {Optivent }}\right)$ was $0.15+0.96$ multiplied by the end-expiratory esophageal pressure measured by the dedicated system (Pes,ee Dedicated $\left.\left(\mathrm{P}<0.0001, \mathrm{r}^{2}=0.99\right) ; \mathrm{B}\right)$ Bland-Altman plot of the end-expiratory esophageal pressure obtained by Optivent and by the dedicated system. The $\mathrm{x}$ axis shows the mean of the two measurements and the y axis shows the difference between the two measurements: mean difference $0.2 \mathrm{cmH}_{2} \mathrm{O}(95 \% \mathrm{CI}: 0.2$ to 0.3$)$, with limits of agreement from $-0.4 \mathrm{cmH}_{2} \mathrm{O}(95 \% \mathrm{CI}$ : -0.5 to -0.3$)$ to $0.9 \mathrm{cmH}_{2} \mathrm{O}(95 \% \mathrm{CI}: 0.8$ to 1.0$)$; C) linear regression plot between the bedside system and the dedicated system. The end-expiratory esophageal pressure obtained by the bedside system (Pes,ee $e_{\text {Bedside }}$ ) was $0.14+1.00$ multiplied by the end-expiratory esophageal pressure measured by the dedicated system (Pes,ee $\left.e_{\text {Dedicated }}\right)(P<0.0001$, $\left.\mathrm{r}^{2}=0.95\right)$; D) Bland-Altman plot of the end-expiratory esophageal pressure obtained by the bedside system and by the dedicated system. The $\mathrm{x}$ axis shows the mean of the two measurements and the $\mathrm{y}$ axis shows the difference between the two measurements: mean difference $-0.1 \mathrm{cmH}_{2} \mathrm{O}(95 \% \mathrm{CI}:-0.3$ to 0.1$)$, with limits of agreement from $-1.9 \mathrm{cmH}_{2} \mathrm{O}(95 \% \mathrm{CI}:-2.2$ to -1.6$)$ to $1.7 \mathrm{cmH}_{2} \mathrm{O}(95 \% \mathrm{CI}: 1.4$ to 2.0$)$.

\section{Lung stress}

The mean lung stress values, respectively computed with data acquired by the dedicated system, the bedside system and by Optivent, were $14.0 \pm 5.8,15.0 \pm 6.6$, and $15.0 \pm 6.1 \mathrm{cmH}_{2} \mathrm{O}$. As shown in Figure 3, both Optivent and the bedside system exhibited a high level of correlation with the dedicated system $\left(\mathrm{r}^{2}=0.97, \mathrm{P}<0.0001\right.$ and $\mathrm{r}^{2}=0.93, \mathrm{P}<0.0001$, respectively). The BlandAltman plot showed a bias of $-0.9 \mathrm{cmH}_{2} \mathrm{O}(95 \%$ CI: -1.1 to -0.7$)$, with limits of agreement $( \pm 1.96$ SD) from $-3.0 \mathrm{cmH}_{2} \mathrm{O}(95 \% \mathrm{CI}:-3.3$ to -2.7$)$ to $1.1 \mathrm{cmH}_{2} \mathrm{O}(95 \% \mathrm{CI}: 0.8$ to 1.4$)$ for the Optivent compared with the dedicated system, and a bias of $-1.5 \mathrm{cmH}_{2} \mathrm{O}$ (95\% CI: -1.8 to -1.2$)$, with limits of agreement $( \pm 1.96 \mathrm{SD})$ from $-4.4 \mathrm{cmH}_{2} \mathrm{O}(95 \%$ CI: -4.9 to -3.9$)$ to $1.4 \mathrm{cmH}_{2} \mathrm{O}(95 \% \mathrm{CI}: 0.9$ to 1.9) for the bedside system compared with the dedicated system (Figure 3). Linear regression and Bland-Altman plots of Optivent compared to the bedside system are shown in Supplementary Digital Material 5 (Supplementary Figure 4).

\section{Discussion}

The present study showed that, in mechanically ventilated ARDS patients, the esophageal pres- 


\section{COPYRIGHT $^{\circledR} 2020$ EDIZIONI MINERVA MEDICA}

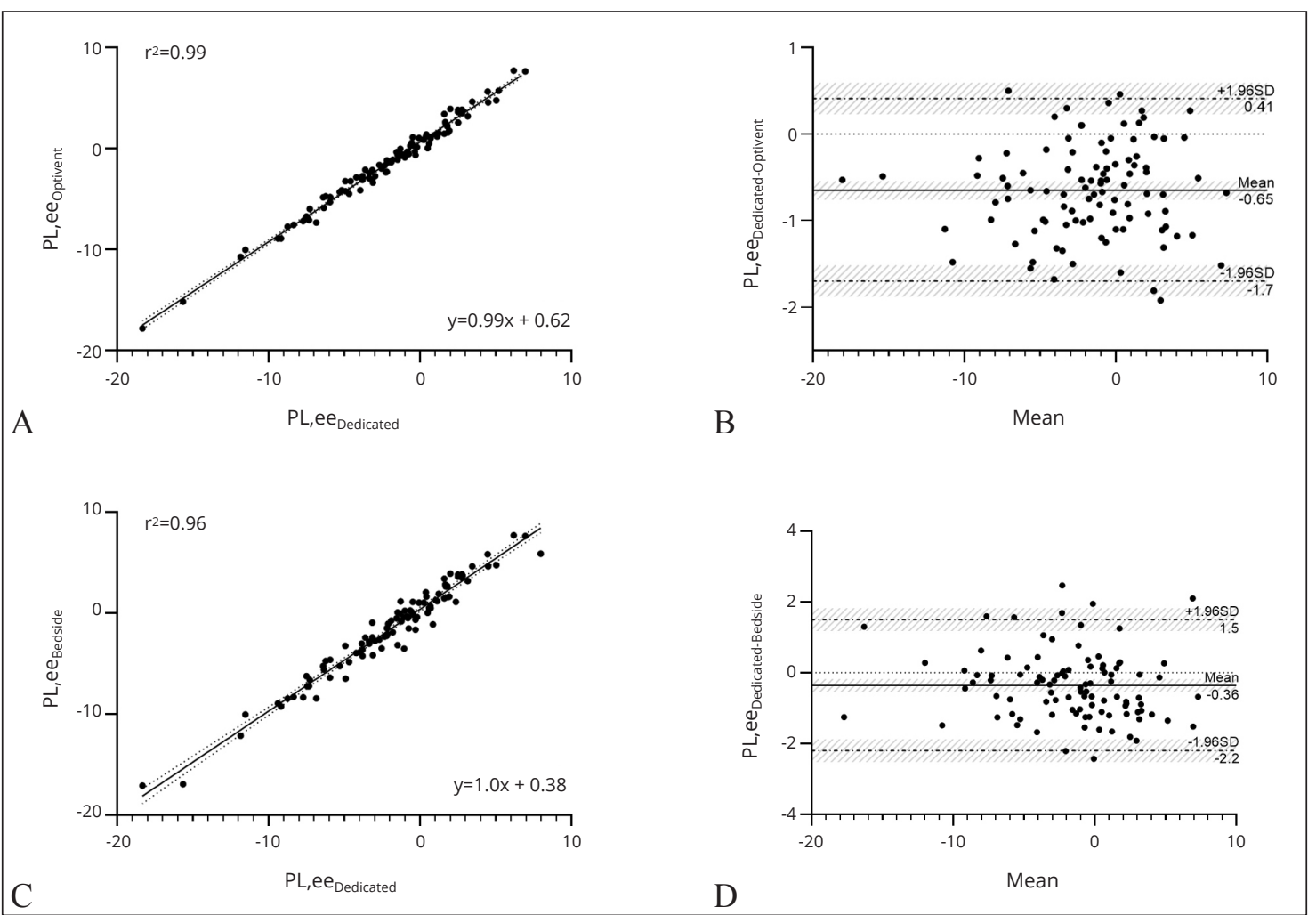

Figure 2.-Accuracy of Optivent and of the bedside system in measuring end-expiratory transpulmonary pressure compared to the dedicated system. A) Linear regression plot between Optivent and the dedicated system. The end-expiratory transpulmonary pressure obtained by Optivent $\left(\mathrm{PL}, \mathrm{ee}_{\text {Optivent }}\right)$ was $0.62+0.99$ multiplied by the end-expiratory esophageal pressure measured by the dedicated system (PL,ee Dedicated $\left(\mathrm{P}<0.0001, \mathrm{r}^{2}=0.99\right)$; B) Bland-Altman plot of the end-expiratory transpulmonary pressure obtained by Optivent and by the dedicated system. The $\mathrm{x}$ axis shows the mean of the two measurements and the $\mathrm{y}$ axis shows the difference between the two measurements: mean difference $-0.6 \mathrm{cmH}_{2} \mathrm{O}(95 \% \mathrm{CI}:-0.8$ to -0.5$)$, with limits of agreement from $-1.7 \mathrm{cmH}_{2} \mathrm{O}(95 \% \mathrm{CI}$ : -1.9 to -1.5$)$ to $0.4 \mathrm{cmH}_{2} \mathrm{O}(95 \%$ CI: 0.2 to 0.6$)$; C) linear regression plot between the bedside system and the dedicated system. The end-expiratory transpulmonary pressure obtained by the bedside system (PL,ee Bedside ) was $0.38+1.00$ multiplied by the end-expiratory transpulmonary pressure measured by the dedicated system (PL,ee $\left.e_{\text {Dedicated }}\right)\left(\mathrm{P}<0.0001, \mathrm{r}^{2}=0.96\right)$; D) Bland-Altman plot of the end-expiratory transpulmonary pressure obtained by the bedside system and by the dedicated system. The $\mathrm{x}$ axis shows the mean of the two measurements and the $\mathrm{y}$ axis shows the difference between the two measurements: mean difference $-0.4 \mathrm{cmH}_{2} \mathrm{O}(95 \% \mathrm{CI}$ : -0.6 to -0.2$)$, with limits of agreement from $-2.2 \mathrm{cmH}_{2} \mathrm{O}(95 \% \mathrm{CI}:-2.5$ to -1.9$)$ to $1.5 \mathrm{cmH}_{2} \mathrm{O}(95 \% \mathrm{CI}: 1.2$ to 1.8$)$.

sure values and its derived variables (end-expiratory transpulmonary pressure and lung stress), measured by a dedicated manual device, considered as gold standard, are well correlated both with a new automatic system (Optivent) and with a bedside equipment.

According to the respiratory mechanics model, transpulmonary pressure, corresponding to the pressure necessary to distend the lung, is one of the most relevant determinants in the pathogenesis of VILI.1, 2, 18 Ideally, the transpulmonary pressure should be calculated as the difference between the airway and the pleural pressure. Due to the difficulty in assessing the pleural pressure, the esophageal pressure has been considered an adequate non-invasive surrogate. ${ }^{11,12}$ The changes in pleural pressure are accurately detected by the changes in esophageal pressure. $4,11,20$ Nowadays, several types of esophageal balloon catheters equipped with or without a nasogastric feeding tube are commercially available. A bench study comparing different types of esophageal balloon catheters at different external pressures reported a high accuracy among measurements. It is worth to remind that a known amount of air should be inflated, according to the size of the balloon and to different conditions of intrathoracic pressure; 


\section{COPYRIGHT $^{\odot} 2020$ EDIZIONI MINERVA MEDICA}
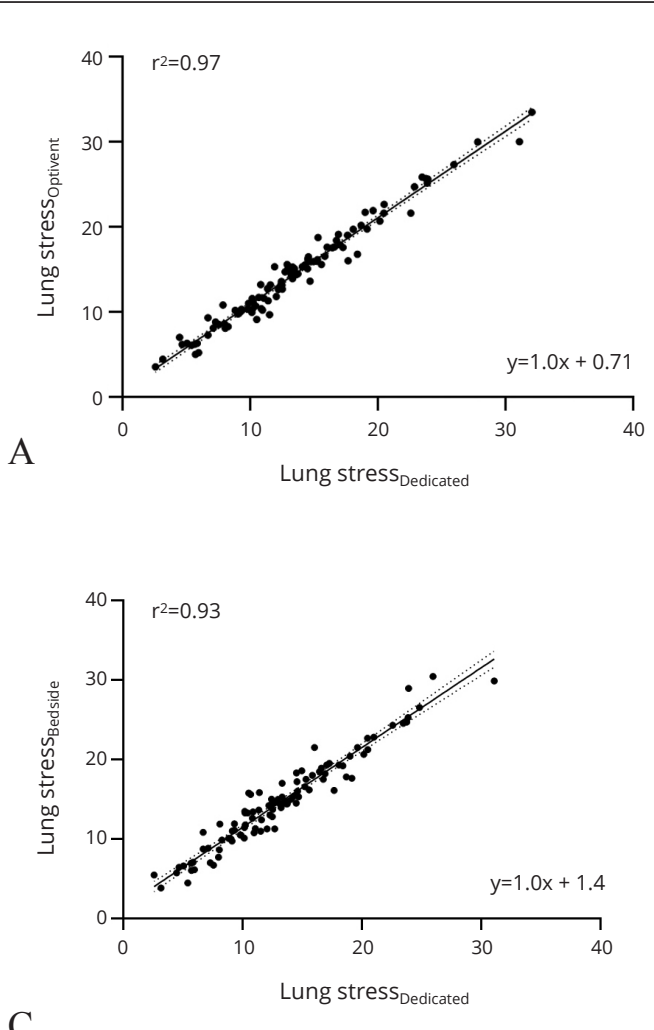

C

Figure 3.-Accuracy of Optivent and of the bedside system in measuring lung stress compared to the dedicated system. A) Linear regression plot between Optivent and the dedicated system. Lung stress obtained by Optivent (Lung stress (ptivent $_{\text {) }}$ was $0.71+1.00$ multiplied by lung stress measured by the dedicated system (Lung stress $\left.{ }_{\text {Dedicted }}\right)\left(\mathrm{P}<0.0001, \mathrm{r}^{2}=0.97\right)$; $\left.\mathrm{B}\right)$ Bland-Altman plot of lung stress obtained by Optivent and by the dedicated system. The $\mathrm{x}$ axis shows the mean of the two measurements and the y axis shows the difference between the two measurements: mean difference $-0.9 \mathrm{cmH}_{2} \mathrm{O}(95 \% \mathrm{CI}$ : -1.1 to -0.7$)$, with limits of agreement from $-3.0 \mathrm{cmH}_{2} \mathrm{O}(95 \% \mathrm{CI}:-3.3$ to -2.7$)$ to $1.1 \mathrm{cmH}_{2} \mathrm{O}(95 \% \mathrm{CI}: 0.8$ to 1.4$)$; C) linear regression plot between the bedside system and the dedicated system. Lung stress obtained by the bedside system (Lung stress $_{\text {Bedside }}$ ) was $1.40+1.00$ multiplied by lung stress measured by the dedicated system (Lung stress $\left.\mathrm{sedicated}\right)(\mathrm{P}<0.0001$, $\mathrm{r}^{2}=0.93$ ); D) Bland-Altman plot of lung stress obtained by the bedside system and by the dedicated system. The $\mathrm{x}$ axis shows the mean of the two measurements and the y axis shows the difference between the two measurements: mean difference $-1.5 \mathrm{cmH}_{2} \mathrm{O}(95 \% \mathrm{CI}:-1.8$ to -1.2$)$, with limits of agreement from $-4.4 \mathrm{cmH}_{2} \mathrm{O}(95 \% \mathrm{CI}:-4.9$ to -3.9$)$ to $1.4 \mathrm{cmH}_{2} \mathrm{O}(95 \%$ CI: 0.9 to 1.9 ).

however, this should not have affected our main results, because measurements were performed in static conditions. ${ }^{21}$ Despite the evidence of the possible utility of esophageal pressure in the management of mechanical ventilation, measurement of esophageal pressure is not often performed, mainly due to the absence of a userfriendly dedicated system. ${ }^{11,12}$ The esophageal pressure could be measured by a mechanical ventilator with an additional specific side port, or by a dedicated system (usually home-made), or by a pressure transducer connected to an hemodynamic monitor. We compared data resulting from a home-made "dedicated system", commonly applied in our clinical research as gold standard, to a new commercially available automatic system and to a bedside system. In the present study we used only one type of esophageal balloon catheter filled with a fixed amount of air, located in the lower part of the esophagus.

Thus, the possibility to apply an automatic system or a bedside system as reliable devices for esophageal pressure measurement, should increase the use of esophageal pressure which has been reported to be less than $1 \%$ of ARDS patients. ${ }^{22}$ In our clinical practice we commonly apply a dedicated system, that although has a 


\section{COPYRIGHT $^{\circledR} 2020$ EDIZIONI MINERVA MEDICA}

good accuracy; however, this system requires an in-vitro calibration, a software with a dedicated pressure transducer and, in addition, it cannot provide real-time data.

The measurement of esophageal pressure is required to compute the transpulmonary pressure. In the computation of transpulmonary pressure, we assume that the esophageal pressure should reflect the pleural pressure in all the lung regions. However, due to the presence of a vertical gradient of pleural pressure, the weight of the mediastinum, the abdominal pressure and the tone of the esophagus, the esophageal pressure reflects the pleural pressure of the middle lung regions. ${ }^{23-25}$ Despite these uncertainties 26,27 it has been proposed to titrate the PEEP in ARDS patients in order to have a positive end-expiratory transpulmonary pressure, so as to limit the atelectrauma. ${ }^{17,} 28$ Currently, opposite findings have been reported, a first study found a better oxygenation and compliance when PEEP was set to obtain a positive end-expiratory transpulmonary pressure value, while a subsequent study was not able to show any difference in gas exchange and in outcome.17, 28 In the present study, both the measurements of esophageal pressure and of the end-expiratory transpulmonary pressure resulted repeatable and accurate by using both the bedside system and the Optivent system compared with the gold standard.

We also computed the lung stress according to the elastance-derived method as the product of end-inspiratory airway pressure and the ratio of lung to respiratory system elastance (Lung stress $=$ end-inspiratory airway pressure $\mathrm{x}$ lung elastance/respiratory system elastance). ${ }^{4,5}$ This method is able to compute the lung stress, as the total pressure inside the lung due to PEEP and tidal volume. ${ }^{5}$ By using this method, Grasso et al. reported, in a small group of ARDS patients, the possibility to apply higher PEEP levels avoiding the lung overstress compared to the simple measurements of plateau airway pressure as safe limit. ${ }^{29}$ Thus, this strategy should optimize the lung recruitment while avoiding the lung overdistension.

Similarly to the esophageal pressure and to the end-expiratory transpulmonary pressure find- ings, we found a good accuracy for lung stress assessment with the Optivent system and the bedside system compared to the dedicated system. Moreover, the limits of agreement of the lung stress assessment using Optivent, can be considered clinically acceptable to detect overdistension.

\section{Limitations of the study}

Possible limitations of this study are: firstly, the use of different mechanical ventilators, that could have increased the inter-variability of the measurements of tidal volume and airway pressure; secondly the esophageal pressure and the derived variables were measured only during passive conditions. Although slight differences in terms of sample rate of pressure transducers and filter of frequency among the three systems they cannot interfere at different pressure values because we performed our measurements in static conditions at the end of an expiratory and inspirator pause of 6-8 seconds and we used the mean values of four pauses.

\section{Conclusions}

Both Optivent and the bedside system, which requires a mechanical ventilator with an hemodynamic monitor, demonstrate clinical acceptability in measuring esophageal pressure and its derived variables. The possibility to apply one of these systems could make the measurement of esophageal pressure easier, with a consequent wider application in clinical practice.

\section{What is known}

- Although esophageal pressure measurement could help clinicians to improve the ventilatory management of ARDS patients by evaluating the lung stress in order to reduce barotrauma and the end-expiratory transpulmonary pressure to titrate PEEP, it has been mainly used in clinical research.

- Several previous studies reported that the changes in pleural pressure has been adequately assessed by the changes in esophageal pressure. 


\section{COPYRIGHT $^{\circ} 2020$ EDIZIONI MINERVA MEDICA}

\section{What is new}

- Both Optivent and the bedside system, which requires a mechanical ventilator and a hemodynamic monitor, present a clinical acceptability for the measurements of esophageal pressure, end-expiratory transpulmonary pressure and lung stress compared to a dedicated system taken as gold standard.

- The possibility to apply one of these systems could make the measurement of esophageal pressure at bedside easier for the physicians.

- A wider use of esophageal pressure measurements could reduce the ventilator-induced lung injury and improve outcome in ventilated patients by understanding the pathophysiological alteration of the respiratory system.

\section{References}

1. Chiumello D, Brochard L, Marini JJ, Slutsky AS, Mancebo J, Ranieri VM, et al. Respiratory support in patients with acute respiratory distress syndrome: an expert opinion. Crit Care 2017;21:240.

2. Fan E, Del Sorbo L, Goligher EC, Hodgson CL, Munshi L, Walkey AJ, et al.; American Thoracic Society, European Society of Intensive Care Medicine, and Society of Critical Care Medicine. An official American Thoracic Society/European Society of intensive care medicine/society of critical care medicine clinical practice guideline: mechanical ventilation in adult patients with acute respiratory distress syndrome. Am J Respir Crit Care Med 2017;195:1253-63.

3. Slutsky AS, Ranieri VM. Ventilator-induced lung injury. N Engl J Med 2013;369:2126-36.

4. Chiumello D, Cressoni M, Colombo A, Babini G, Brioni $\mathrm{M}$, Crimella F, et al. The assessment of transpulmonary pressure in mechanically ventilated ARDS patients. Intensive Care Med 2014;40:1670-8.

5. Gattinoni L, Chiumello D, Carlesso E, Valenza F. Benchto-bedside review: chest wall elastance in acute lung injury/acute respiratory distress syndrome patients. Crit Care 2004;8:350-5.

6. Pelosi P, Cereda M, Foti G, Giacomini M, Pesenti A. Alterations of lung and chest wall mechanics in patients with acute lung injury: effects of positive end-expiratory pressure. Am J Respir Crit Care Med 1995;152:531-7.

7. Gattinoni L, Pelosi P, Suter PM, Pedoto A, Vercesi P, Lissoni A. Acute respiratory distress syndrome caused by pulmonary and extrapulmonary disease. Different syndromes? Am J Respir Crit Care Med 1998;158:3-11.

8. Malbrain ML, Chiumello D, Pelosi P, Bihari D, Innes R, Ranieri VM, et al. Incidence and prognosis of intraabdominal hypertension in a mixed population of critically ill patients: a multiple-center epidemiological study. Crit Care Med 2005;33:315-22.
9. Chiumello D. Intra-abdominal pressure in critically ill patients: it is worthwhile to measure? Minerva Anestesiol 2007;73:445-6.

10. Chiumello D, Marino A, Cressoni M, Mietto C, Berto V, Gallazzi E, et al. Pleural effusion in patients with acute lung injury: a CT scan study. Crit Care Med 2013;41:935-44.

11. Akoumianaki E, Maggiore SM, Valenza F, Bellani G, Jubran A, Loring SH, et al.; PLUG Working Group (Acute Respiratory Failure Section of the European Society of Intensive Care Medicine). The application of esophageal pressure measurement in patients with respiratory failure. Am J Respir Crit Care Med 2014;189:520-31.

12. Mauri T, Yoshida T, Bellani G, Goligher EC, Carteaux G, Rittayamai N, et al.; PLeUral pressure working Group (PLUG-Acute Respiratory Failure section of the European Society of Intensive Care Medicine). Esophageal and transpulmonary pressure in the clinical setting: meaning, usefulness and perspectives. Intensive Care Med 2016;42:1360-73.

13. Dornhorst AC, Leathart GL. A method of assessing the mechanical properties of lungs and air-passages. Lancet 1952;2:109-11.

14. Cherniack RM, Farhi LE, Armstrong BW, Proctor DF. A comparison of esophageal and intrapleural pressure in man. J Appl Physiol 1955;8:203-11.

15. Ferguson ND, Fan E, Camporota L, Antonelli M, Anzueto A, Beale R, et al. The Berlin definition of ARDS: an expanded rationale, justification, and supplementary material. Intensive Care Med 2012;38:1573-82.

16. Chiumello D, Consonni D, Coppola S, Froio S, Crimella F, Colombo A. The occlusion tests and end-expiratory esophageal pressure: measurements and comparison in controlled and assisted ventilation. Ann Intensive Care 2016;6:13.

17. Talmor D, Sarge T, Malhotra A, O’Donnell CR, Ritz $\mathrm{R}$, Lisbon A, et al. Mechanical ventilation guided by esophageal pressure in acute lung injury. N Engl J Med 2008;359:2095-104.

18. Chiumello D, Carlesso E, Cadringher P, Caironi P, Valenza F, Polli F, et al. Lung stress and strain during mechanical ventilation for acute respiratory distress syndrome. Am J Respir Crit Care Med 2008;178:346-55.

19. Bland JM, Altman DG. Statistical methods for assessing agreement between two methods of clinical measurement. Lancet 1986;1:307-10.

20. Pasticci I, Cadringher P, Giosa L, Umbrello M, Formenti $\mathrm{P}$, Macri MM, et al. Determinants of the esophageal-pleural pressure relationship in humans. J Appl Physiol (1985) 2020;128:78-86.

21. Mojoli F, Chiumello D, Pozzi M, Algieri I, Bianzina S, Luoni S, et al. Esophageal pressure measurements under different conditions of intrathoracic pressure. An in vitro study of second generation balloon catheters. Minerva Anestesiol 2015;81:855-64.

22. Bellani G, Laffey JG, Pham T, Fan E, Brochard L, Esteban A, et al.; LUNG SAFE Investigators; ESICM Trials Group. Epidemiology, Patterns of Care, and Mortality for Patients With Acute Respiratory Distress Syndrome in Intensive Care Units in 50 Countries. JAMA 2016;315:788-800.

23. Yoshida T, Amato MB, Grieco DL, Chen L, Lima CA, Roldan R, et al. Esophageal manometry and regional transpulmonary pressure in lung injury. Am J Respir Crit Care Med 2018;197:1018-26.

24. Pelosi P, Goldner M, McKibben A, Adams A, Eccher G, Caironi $\mathrm{P}$, et al. Recruitment and derecruitment during acute 


\section{COPYRIGHT $^{\odot} 2020$ EDIZIONI MINERVA MEDICA}

respiratory failure: an experimental study. Am J Respir Crit Care Med 2001;164:122-30.

25. Hedenstierna G. Esophageal pressure: benefit and limitations. Minerva Anestesiol 2012;78:959-66.

26. Brochard L. Measurement of esophageal pressure at bedside: pros and cons. Curr Opin Crit Care 2014;20:39-46.

27. Loring SH, Topulos GP, Hubmayr RD. Transpulmonary pressure: the importance of precise definitions and limiting assumptions. Am J Respir Crit Care Med 2016;194:1452-7.

28. is Beitler JR, Sarge T, Banner-Goodspeed VM, Gong
MN, Cook D, Novack V, et al.; EPVent-2 Study Group. Effect of Titrating Positive End-Expiratory Pressure (PEEP) With an Esophageal Pressure-Guided Strategy vs an Empirical High PEEP-Fio2 Strategy on Death and Days Free From Mechanical Ventilation Among Patients With Acute Respiratory Distress Syndrome: A Randomized Clinical Trial. JAMA 2019;321:846-57.

29. Grasso S, Terragni P, Birocco A, Urbino R, Del Sorbo L, Filippini C, et al. ECMO criteria for influenza A (H1N1)associated ARDS: role of transpulmonary pressure. Intensive Care Med 2012;38:395-403.

Conflicts of interest.-Davide Chiumello participated in the development of the esophageal catheter Nutrivent, he is involved in a University research spin-off and he received a honorarium as member of the advisory board. All other authors have no conflicts of interest to declare.

Funding.-Unrestricted grant from SIDAM Srl. (Modena, Italy).

Authors' contributions.- Study concept and design: Davide Chiumello, Silvia Coppola; data acquisition: Alessio Caccioppola, Tommaso Pozzi, Andrea C. Lusardi, Valentina De Giorgis, Valentina Galanti, Erica Ferrari; data analysis and interpretation: Alessio Caccioppola, Tommaso Pozzi, Davide Chiumello; critical revision of manuscript: Alessio Caccioppola, Tommaso Pozzi, Davide Chiumello, Silvia Coppola. All authors read and approved the final version of the manuscript.

Comment in: De Blasi RA, Fiorelli S. Measurement of esophageal pressure: possible limits to its clinical application. Minerva Anestesiol 2020;86:1008-10. DOI: 10.23736/S0375-9393.20.15040-5.

History.-Article first published online: June 12, 2020. - Manuscript accepted: June 5, 2020. - Manuscript revised: May 25, 2020. Manuscript received: January 28, 2020.

Supplementary data.-For supplementary materials, please see the HTML version of this article at www.minervamedica.it 